\title{
Percutaneous treatment of mitral regurgitation recurrence after mitral valve surgery
}

\author{
Julio Echarte-Morales ${ }^{1}$, Carlos Minguito-Carazo1, Tomás Benito-González', Rodrigo Estévez-Loureiro², \\ Carmen Garrote-Coloma ${ }^{1}$, Armando Pérez de Prado ${ }^{1}$, Felipe Fernández-Vázquez ${ }^{1}$ \\ 'Department of Cardiology, University Hospital of León, León 24071, Spain. \\ 2Department of Cardiology, University Hospital Alvaro Cunqueiro, Vigo 36312, Spain.
}

Correspondence to: Dr. Tomás Benito-González, MD, Department of Cardiology, University Hospital of León, Altos de Nava SN, León 24071, Spain. E-mail: tomasbenito@outlook.com

How to cite this article: Echarte-Morales J, Minguito-Carazo C, Benito-González T, Estévez-Loureiro R, Garrote-Coloma C, Prado APd, Fernández-Vázquez F. Percutaneous treatment of mitral regurgitation recurrence after mitral valve surgery. Vessel Plus 2021;5:54. https://dx.doi.org/10.20517/2574-1209.2020.105

Received: 9 Dec 2020 First Decision: 17 Mar 2021 Revised: 7 Apr 2021 Accepted: 21 Apr 2021 Published: 5 Nov 2021

Academic Editor: Manel Sabate Copy Editor: Xi-Jun Chen Production Editor: Xi-Jun Chen

\begin{abstract}
Mitral regurgitation is one of the most common cardiac valve disorders worldwide and the second most frequent indication of cardiac surgery for heart valve disease. During the last decades, open-heart mitral valve repair and replacement have been considered the sole and gold standard invasive therapy for this complex disorder. However, a significant proportion of patients experiences recurrence of mitral regurgitation during long-term follow-up, which entails an important increase in morbidity and mortality. In this scenario, percutaneous therapies to treat mitral regurgitation have become an appealing alternative to conventional surgery given high risk for repeat surgery. The present review describes current evidence of transcatheter mitral valve repair and replacement therapies to treat mitral regurgitation recurrence after surgery.
\end{abstract}

Keywords: Mitral regurgitation, mitral valve repair, mitral valve replacement, percutaneous mitral valve repair, transcatheter mitral valve replacement, valve-in-valve, valve-in-ring, percutaneous paravalvular leak closure

\section{INTRODUCTION}

Mitral regurgitation (MR) is one of the most common cardiac valve disorders in the developed world and the second most frequent indication for cardiac surgery due to heart valve disease (HVD ${ }^{[1]}$. Depending on 
the etiology, it can be classified as primary (PMR) or secondary MR (SMR). In PMR, the valvular incompetence is caused by organic disease of any of the mitral valve (MV) components, and myxomatous degeneration is its most common cause ${ }^{[2]}$. Conversely, SMR is characterized by normal MV leaflets and tendinous cord structure, and MR results from annular dilatation and/or papillary muscle dysfunction due to left ventricular (LV) and/or atrial disease ${ }^{[3]}$. Conventional MV surgery (MVS) is currently the treatment of choice for symptomatic patients with PMR while the indication for operation in SMR is now limited to those patients undergoing simultaneous coronary artery bypass graft ${ }^{[4]}$. Recurrence of significant MR after MVS can be observed in up to $10 \%-30 \%$ of cases during follow-up, resulting in an increased morbidity and mortality ${ }^{[s]}$. Conservative management of these patients is related to adverse outcome, and reintervention is infrequently performed given the high surgical risk. In this scenario, transcatheter techniques for MV repair or replacement have become a reasonable alternative in patients at high surgical risk. The present review discusses outcomes of MVS and percutaneous alternatives to approach MR recurrence after surgery.

\section{MITRAL VALVE SURGERY FOR MITRAL REGURGITATION}

\section{Primary mitral regurgitation}

Most recent guidelines for HVD recommend MVS in symptomatic patients with severe PMR and in those who remain asymptomatic but show adverse LV remodeling (LV ejection fraction $\leq 60 \%$ or LV end-systolic diameter $\geq 40 \mathrm{~mm})^{[4]}$. Intervention may be also considered in asymptomatic patients who develop atrial fibrillation or moderate to severe pulmonary hypertension ${ }^{[6]}$.

In patients with symptomatic PMR, surgical MV repair (MVr) has shown to improve expected prognosis of untreated patients and is associated with better short- and long-term outcomes compared to surgical MV replacement $(\mathrm{MVR})^{[7]}$. In a recent review of 12 different studies comparing both surgical approaches in patients with PMV, short-term mortality ranged from $0 \%$ to $4 \%$ and from $2.1 \%$ to $13.9 \%$ after MVr and MVR, respectively ${ }^{[8]}$. Some of the predictors of likelihood of successful MVr are presented in Table $1^{[9]}$. The ideal anatomy for MVr corresponds to cases of MR due to fibroelastic deficiency or focal myxomatous prolapse. On the contrary, MVR should be considered in cases with low periprocedural risk and severe MV disease with a non-favorable anatomy.

In highly experienced centers, most cases of PMR can undergo MVr with favorable outcomes and an associated periprocedural mortality below $2 \%^{[10]}$. Nevertheless, there are few centers worldwide that perform enough procedures to achieve these outcomes. Despite MVr being the preferred surgical approach for PMR, approximately $30 \%$ of patients receive a prosthetic valve because $\mathrm{MVr}$ is deemed not feasible, and this occurs more frequently in low-volume centers ${ }^{[10]}$.

\section{Secondary mitral regurgitation}

SMR is generally related to a LV disease, such as dilated cardiomyopathy or ischemic heart disease $\mathrm{e}^{[3]}$. For this reason, optimal medical therapy for heart failure (HF) is the first line treatment for these patients, leading in many cases to reverse LV remodeling and, consequently, a decrease in the severity of SMR. In symptomatic subjects despite optimal medical therapy, including cardiac resynchronization if indicated, percutaneous mitral valve repair (PMVR) can be considered in the absence of signs of end-stage $\mathrm{HF}^{[4]}$. To date, no clinical benefit in hard outcomes has been reported after MVS in patients with isolated SMR; therefore, this approach is only suggested in patients undergoing concomitant surgical coronary revascularization ${ }^{[1]}$. In addition, $\mathrm{MVr}$ has not proven to be superior to MVR in this scenario. Goldstein et al. ${ }^{[12]}$ compared both surgical approaches in a randomized controlled trial (RCT) that included 251 patients with ischemic SMR. After two years of follow up, there were no differences in mortality between both groups, although there were more HF and cardiovascular readmissions in the MVr group, 
Table 1. Morphological characteristics of the mitral valve and its impact on successful mitral valve repair

\begin{tabular}{|c|c|c|c|}
\hline Condition & Ideal & Permissive & Non-permissive \\
\hline Affected leaflet & Posterior & Anterior or both & Both \\
\hline Leaflet calcification & None & Mild & Moderate-severe \\
\hline Ring calcification & None & Mild-moderate & Severe \\
\hline $\begin{array}{l}\text { Subvalvular } \\
\text { apparatus }\end{array}$ & Normal & Mild diffuse or moderate focal thickening & Severe and diffuse thickening with retraction \\
\hline $\begin{array}{l}\text { Regurgitation } \\
\text { mechanism }\end{array}$ & $\begin{array}{l}\text { Carpentier II (FED or focal } \\
\text { prolapse) }\end{array}$ & $\begin{array}{l}\text { Carpentier I (IE) } \\
\text { Carpentier II (Barlow disease) } \\
\text { Carpentier III (mild restriction/thickening } \\
\text { of leaflets) }\end{array}$ & $\begin{array}{l}\text { Carpentier I (active IE with severe MV } \\
\text { destruction) } \\
\text { Carpentier IIIA (severe calcification of both } \\
\text { leaflets) } \\
\text { Carpentier IIIB (severe restriction, inferior wall } \\
\text { aneurysm) }\end{array}$ \\
\hline Other features & None & $\begin{array}{l}\text { Previous heart surgery, congenital } \\
\text { anomalies }\end{array}$ & $\begin{array}{l}\text { Papillary muscle rupture, MV reoperation with } \\
\text { severe tissue loss }\end{array}$ \\
\hline
\end{tabular}

FED: Fibroelastic deficiency; IE: infective endocarditis; MV: mitral valve; MVr: mitral valve repair.

mainly driven by a high MR recurrence $(58.5 \% \text { vs. } 3.8 \%)^{[12]}$.

Quantification of MR requires the integration of quantitative and qualitative echocardiographic parameters and can be particularly challenging after MVr due to the distortion of native MV anatomy and the shadowing of the implanted annulus. To date, $2 \mathrm{D}$ and $3 \mathrm{D}$ contract vein are the quantitative parameters with highest evidence.

\section{Recurrence of mitral regurgitation after surgery}

Mitral valve repair

Overall, recurrence of MR after MVr occurs in approximately 10\%-30\% of patients in long-term followup $^{[5]}$. Technical issues may lead to early MR recurrence, while long-term MVr failure is usually a consequence of progression of the underlying MV disease ${ }^{[13]}$. Many factors may impact the probability of $M R$ recurrence after $M V r$, including the etiology of MR, the case volume experience of the operator team, the surgical technique, anatomical features of the MV, and clinical comorbidities. Some of these factors are summarized in Table 2, grouped by the etiology of MR.

In the studies carried out during the first decade of this century, only 50\% of patients with PMR undergoing MVr remained free of moderate to severe MR over long-term follow-up. However, as a result of the improvement in MVr techniques in recent years, the recurrence rate has decreased substantially, being as low as $13.3 \%$ at 15 years in some series ${ }^{[14]}$. Conversely, results of MVr in SMR are much more modest, especially in ischemic SMR, and recurrence of significant MR may exceed 50\% at 2-year follow up even in the setting of RCT and high-volume centers ${ }^{[12]}$. In fact, operator's procedural volume has shown to be a major independent determinant of outcomes. In a recent study including 5745 patients with PMR, more surgical experience was independently associated with longer survival and reduced need for MV reoperation within 12 months of follow-up (HR $=0.45,95 \%$ CI: $0.26-0.76, P=0.003)^{[15]}$.

Beyond its frequency, recurrence of moderate to severe MR after MVr has been consistently associated with an increased mortality. In two recent observational series, one including 1218 patients with PMR and another one analyzing 261 subjects with SMR, MR recurrence after MVr was significantly related to an increased risk of death in both reports (PMR: $\mathrm{HR}=1.72,95 \% \mathrm{CI}: 1.24-2.39, P=0.002$; SMR: $\mathrm{HR}=3.28$, 95\%CI: $1.87-5.75, P<0.001)^{[5]}$. 
Table 2. Predictors of regurgitation recurrence after mitral valve repair

\begin{tabular}{ll}
\hline PMR & SMR \\
\hline Elderly population & Anterior and posterior myocardial infarction \\
Isolated prolapse of anterior leaflet & Preoperative LVEDD $>70 \mathrm{~mm}$ \\
Advanced myxomatous degeneration & Preoperative LVESD index $>45 \mathrm{~mL} / \mathrm{m}^{2}$ \\
Lack of mitral annuloplasty, chordal shortening & Coaptation depth at discharge $\geq 0.5 \mathrm{~cm}$ \\
Prolonged cardiopulmonary bypass time & QRS $>120 \mathrm{~ms}$ prior to surgery \\
Low volume experience of operator team & Short posterior tethering \\
Systolic pulmonary artery pressure $\geq 50 \mathrm{mmHg}$ & Interpapillary distance $>20 \mathrm{~mm}$ \\
Reduced LVEF & Posterior mitral valve leaflet angle $>40^{\circ}$ \\
\hline
\end{tabular}

PMR: Primary mitral regurgitation; SMR: secondary mitral regurgitation; LVEF: left ventricle ejection fraction; LVEDD: left ventricular end-diastolic diameter; LVESD: left ventricle end systolic diameter.

\section{Mitral valve replacement}

Two main mechanisms can cause recurrence of MR after MVR: degeneration of bioprosthetic valves and para-valvular leaks (PVL) in mechanical prosthesis. Bioprosthesis dysfunction is increasingly common since its use has become more widespread in recent years ${ }^{[1,17]}$. The most frequent cause of bioprosthesis failure is progressive degeneration of the valvular tissue, resulting in severe calcification of the leaflets that can lead to prosthetic insufficiency or stenosis. Recent studies suggest that host immune response may play a major role in the pathogenesis of structural valve degeneration, leading to a combination of rejection-like processes, atherosclerosis, and calcification of native valves.

The annual incidence of PVL after MVR is estimated at $0.2 \%-1.4 \%$, and it more frequently affects mechanical prosthesis ${ }^{[18,19]}$. Severe MV annular calcification, endocarditis, connective tissue disease, and continuous suturing have been associated with a higher incidence of $\mathrm{PVL}^{[20]}$. Clinical symptoms vary and range from asymptomatic to HF and/or hemolysis. In symptomatic patients, medical treatment often fails to provide enough clinical relief and is associated with poor outcomes, prompting invasive management to fix the leak ${ }^{[21]}$.

\section{Redo surgery for MR recurrence}

Reoperation implies an increased rate of prolonged patient ventilation in the postoperative period, renal failure, and stroke. Some of the factors associated with adverse events in this population are severe tricuspid valve regurgitation, cardiogenic shock, the timing of the procedure, and concomitant myocardial revascularization. Onorati et al..$^{[22]}$ reported an operative mortality rate of $12.5 \%$ in a series of 832 patients. The most frequent complications were acute myocardial infarction, acute respiratory failure, and acute renal failure $^{[22]}$. Although some studies have described improvement in terms of adverse events in patients reoperated upon due to the recurrence of MR, most of them have recorded important intra- and postoperative mortality in such individuals ${ }^{[23]}$.

\section{Transcatheter therapies for MR recurrence after surgery}

In recent years, there has been a huge development of percutaneous therapies to treat MR to offer an alternative for symptomatic patients who were not deemed candidates for conventional MVS ${ }^{[24]}$. Similarly, most patients with recurrence of MR following MVS are at high risk for reoperation due to advanced age and multiple comorbidities. In this setting, some transcatheter therapies offer an appealing less invasive approach for these patients, who were previously managed conservatively with poor outcomes ${ }^{[5]}$. These therapies include PMVR, transcatheter mitral valve replacement (TMVR) [valve-in-ring (ViR) or valve-invalve $(\mathrm{ViV})]$, and percutaneous PVL closure. 
Percutaneous mitral valve repair

MitraClip (Abbott, Santa Clara, CA, USA) is a polyester-coated chromium-cobalt device that is advanced via the femoral vein into the left atrium through a transseptal puncture under transesophageal echocardiographic (TEE) guidance ${ }^{[25]}$. Based on the Alfieri surgical technique, the clip grasps the edge of the anterior and posterior leaflets within the central part of the MV at the point where the regurgitant jet originates. If needed, more than one clip can be deployed to further reduce MR in the absence of significantly increased MV gradient. The safety and efficacy of the procedure has been demonstrated in several trials and registries in patients with native MV diseases ${ }^{[25]}$. In this regard, PMVR currently represents the standard of care for patients with SMR and a less invasive alternative for patients with PMR at high risk for conventional surgery ${ }^{[4]}$.

PMVR can also be an alternative for patients who develop significant MR after MVr [Figure 1]. The first experience in this setting was reported by Lim et al. ${ }^{[26]}$ in 2010. In this study, two patients with SMR who had previously received CABG and MV annuloplasty underwent successful PMVR showing persistent reduction in MR and clinical and hemodynamic improvement in mid-term follow-up. More recently, different case series have reported reasonable results with low morbimortality [Table 3 ${ }^{[27-31]}$. In the largest to date reported series, Braun et al..$^{[29]}$ included 57 patients ( $76 \pm 9$ years, STS score $6 \pm 5,52 \%$ SMR) undergoing PMVR after MVr (79\% with annuloplasty ring). The etiology of recurrence in the cases of PMR was recurrent prolapse or flail (50\%), leaflet tethering (27\%), or partial ring dehiscence (23\%), whereas, in patients treated for SMR, leaflet tethering was the most common underlying mechanism (53\%). Patients included in this registry met the following anatomical criteria: mitral valve area $\geq 2.5 \mathrm{~cm}^{2}$, visible mobile length of mitral leaflets $\geq 5 \mathrm{~mm}$, flail height $\leq 10 \mathrm{~mm}$, flail width $\leq 15 \mathrm{~mm}$, and five central or adjacent jet origins.

In this selected cohort, acute procedural success (residual MR $\leq 2+$ ) was achieved in $84 \%$ of patients and did not significantly differ according to the etiology of native MV disease or the technique used for MVr. Significant, although modest, increase in transmitral gradient ( $3.1 \pm 1.4$ to $4.3 \pm 1.5 \mathrm{mmHg}$ ) and decrease in MV area $\left(3.5 \pm 1.2\right.$ to $\left.2.4 \pm 1.0 \mathrm{~cm}^{2}\right)$ were observed after PMVR, with no MAE within in-hospital stay. During a mean follow-up of $15.9 \pm 15.5$ months in 47 patients, six subjects died, $82 \%$ had residual MR $\leq 2+$, and $66 \%$ were in NYHA functional Class I or II.

From a technical perspective, some difficulties may be found during PMVR in patients with prior surgical annuloplasty, which is by far the most common MVr approach nowadays. First, the most common issue is probably that the quality of TEE imaging for procedural guidance is impaired. In some cases, shadowing from the annuloplasty ring may create dropout artifacts and obscure the edge of both leaflets, thus challenging the grasping of the clip. Therefore, additional imaging such as transthoracic or intracardiac echocardiography (ICE) might be needed to achieve successful procedural outcomes. In this regard, Saji et al. ${ }^{[32]}$ reported their experience of PMVR in five patients with failed prior surgical rings using $2 \mathrm{D}$ ICE as an adjunctive imaging guidance given suboptimal TEE imaging alone. They introduced a $9 \mathrm{~F}$ sheath via the femoral artery and placed the ICE catheter in the LV through this sheath, which was rotated afterwards to create a short axis of the MV. The acute procedural success rate was $80 \%$ and no complications related to ICE were documented. The authors concluded that the quality of imaging was good enough to help the procedure and this approach might reduce procedural time in selected cases. Second, the surgical ring might entangle with the clip arms or grippers, requiring meticulous maneuvers under 3D TEE guidance ${ }^{[33]}$. Third, pre-existing annuloplasty ring and/or thickening of neochords might significantly increase the transmitral gradient after clipping, leading to procedural failure ${ }^{[28]}$. In this regard, left atrial hemodynamics and 3D TEE planimetry of the residual MV area may help to determine if that result can be acceptable ${ }^{[33]}$. Fourth, in 
Table 3. Case series of percutaneous mitral valve repair with MitraClip after failing mitral valve repair

\begin{tabular}{|c|c|c|c|c|c|c|c|}
\hline Case series & $\begin{array}{l}\text { Number of } \\
\text { patients }\end{array}$ & $\begin{array}{l}\text { Age } \\
\text { (years) }\end{array}$ & $\begin{array}{l}\text { STS score } \\
(\%)\end{array}$ & $\begin{array}{r}\text { Etio } \\
P\end{array}$ & $\begin{array}{l}\text { native MR } \\
\text { MR (\%) }\end{array}$ & $\begin{array}{l}\text { Main mechanism of } \\
\text { recurrence }\end{array}$ & $\begin{array}{l}\text { Acute procedural } \\
\text { success (MR } \leq 2+) \\
(\%)\end{array}$ \\
\hline Grasso et al. ${ }^{[30]}$ & 6 & 74.8 & 6.2 & 0 & 100 & $\begin{array}{l}\text { Leaflet tethering } \\
\text { (Carpentier IIIB) }\end{array}$ & 100 \\
\hline Estévez et al. ${ }^{[31]}$ & 6 & 69.8 & $\star \star$ & 33.3 & 66.7 & $\begin{array}{l}\text { Leaflet tethering } \\
\text { (Carpentier IIIB) }\end{array}$ & 100 \\
\hline Pleger et al. ${ }^{[27]}$ & 7 & 78 & 7.5 & 0 & 100 & $\begin{array}{l}\text { Leaflet tethering } \\
\text { (Carpentier IIIB) }\end{array}$ & 100 \\
\hline Niikura et al. ${ }^{[28]}$ & 12 & 70 & 6.5 & 91.7 & 8.3 & $\begin{array}{l}\text { Recurrent leaflet prolapse } \\
\text { or flail (Carpentier II) }\end{array}$ & 66.7 \\
\hline Braun et al. ${ }^{[29]}$ & 57 & 76 & 6 & 39 & 52 & $\begin{array}{l}\text { Recurrent leaflet prolapse } \\
\text { or flail (Carpentier II) } \\
\text { Leaflet tethering } \\
\text { (Carpentier IIIB) }\end{array}$ & 84 \\
\hline
\end{tabular}

${ }^{* *}$ Not available. STS: Society Thoracic of Surgeons; PMR: primary mitral regurgitation; FMR: secondary mitral regurgitation; MR: mitral regurgitation.
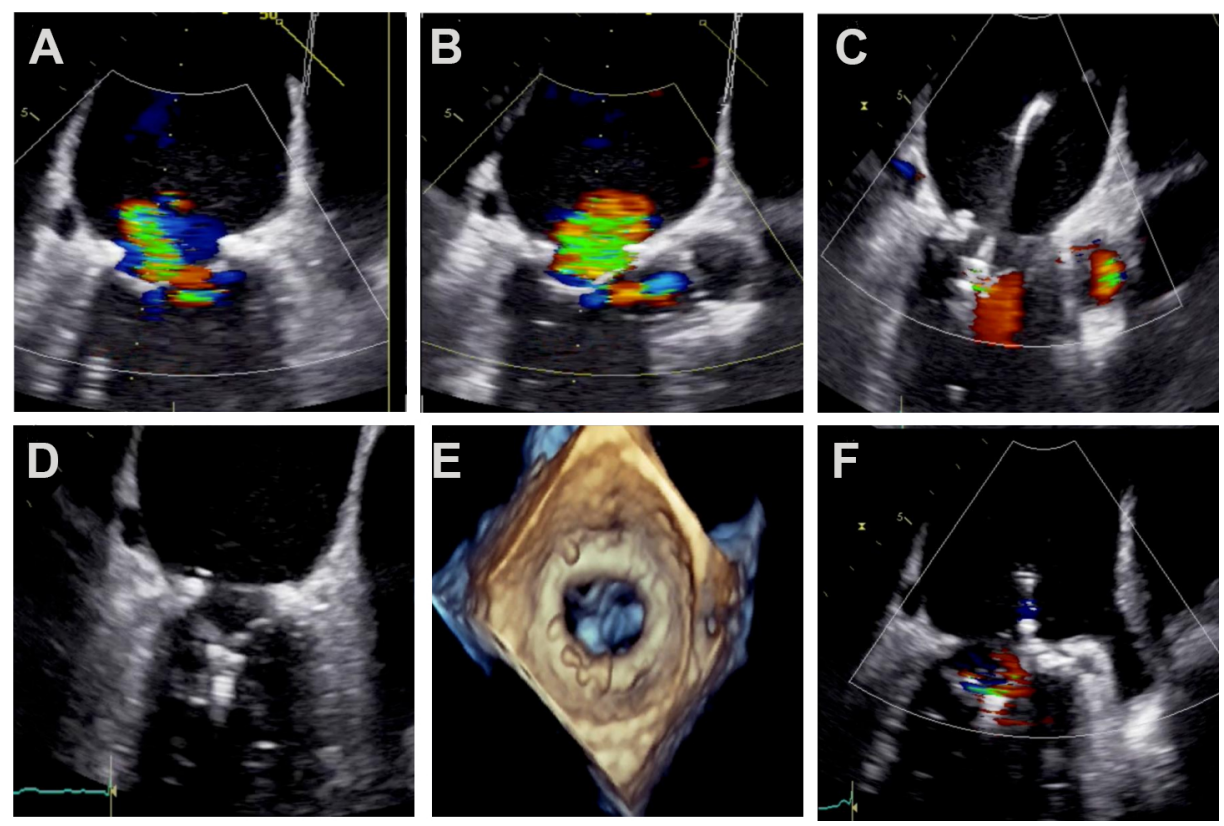

Figure 1. Percutaneous mitral valve repair after surgical mitral valve annuloplasty. (A, B) Transesophageal echocardiogram (TEE) showing severe mitral regurgitation after surgical mitral valve repair. (C-F) TEE showing a significative reduction of mitral regurgitation after MitraClip deployment.

some patients, MVr is carried out by reconstruction of the MV leaflets or subvalvular apparatus with or without concomitant annuloplasty. Among them, resection of some tissue from one or both MV leaflets is relatively common, sometimes preventing conventional MitraClip grasping. Although this unfavorable anatomy should prompt alternative therapies, clipping the leaflet to ring has previously been described as a bailout approach for patients with no alternatives ${ }^{[34]}$. Finally, the dehiscence or rupture of the annuloplasty ring may imply a particularly challenging anatomy for PMVR, although successful procedures in this scenario have been reported ${ }^{[35]}$. 
Despite these technical challenges, Avenatti et al. ${ }^{[36]}$ did not find significant differences in procedural time or outcomes in 12 patients undergoing PMVR after MVr compared to 54 subjects who received MitraClip to treat to native MR. Although available evidence is limited to small registries, PMVR appears to be a safe and effective alternative to conventional surgery in patients with MR recurrence after MVr. In this setting, patient selection may be particularly important, with special focus on preprocedural transmitral gradient and MV area, echocardiographic window, remaining mobile tissue of both leaflets, the presence of ring dehiscence or rupture, and the mechanism of MR recurrence ${ }^{[31]}$.

\section{Transcatheter mitral valve replacement}

Mitral ViV and ViR techniques are based on the implant of dedicated transcatheter prosthesis for the aortic and pulmonary valves in the MV position, with anchoring at previous surgical prosthesis or annuloplasty ring, respectively ${ }^{[37]}$ [Figures 2 and 3]. The transapical route was the first access used for TMVR; however, the transseptal approach is gaining popularity with the introduction of the third and fourth generation of percutaneous prosthetic valves. Compared to transeptal access, the transapical route is associated with a higher incidence of bleeding, respiratory and infectious complications, and a longer recovery period after the procedure ${ }^{[38]}$. Moreover, TMVR through the femoral vein may reduce periprocedural mortality ${ }^{[39]}$.

Different transcatheter prosthesis have been used for mitral VIV or ViR implantation, including balloonexpandable MELODY (Medtronic, Minneapolis, MN, USA) and SAPIEN valves (Edwards Lifesciences, Irvine, CA, USA), mechanically expandable LOTUS valve (Boston Scientific, Marlborough, MA, USA), and inflatable prosthetic heart valve DIRECTFLOW (Direct Flow Medical, Inc., Santa Rosa, CA). To date, balloon expandable SAPIEN valve is by far the most commonly used device and the one with the largest reported evidence. Cheung et al. ${ }^{[40]}$ analyzed short- and long-term outcomes of 23 patients with severe mitral bioprosthetic valve dysfunction (39.1\% MR, 26.1\% mitral stenosis, and 34.8\% both) undergoing transapical ViV due to high risk for redo MVS (STS score $12.1 \% \pm 6.8 \%$ ). A SAPIEN valve was successfully implanted in all patients leading to a significant reduction in transvalvular MV gradient and clinical improvement, with no significant residual MR. At 30 days, all patients were alive, although one patient presented a stroke and six subject had major bleeds during hospitalization. During a median follow up of over two years, survival was $90.4 \%$. One patient needed an early percutaneous reintervention due to atrial migration of the transcatheter valve ${ }^{[40]}$. More recently, Whisenant et al. ${ }^{[39]}$ evaluated one-year outcomes in 1529 patients undergoing SAPIEN 3 mitral ViV replacement. Procedural technical success was achieved in $96.8 \%$ of the cohort and LV outflow tract (LVOT) obstruction was documented in $0.9 \%$ of cases. All-cause mortality was $5.4 \%$ and $16.7 \%$ at 30 days and 1 year, respectively, and, at 12 -month follow-up, over $90 \%$ of patients were in NYHA functional Class I or II.

Compared to ViV procedures, ViR is related to worse outcomes, including lower rates of technical success and higher rates of device embolization, residual MR, LVOT obstruction, and all-cause mortality ${ }^{[41,42]}$. The incidence of recurrent MR after ViR can be over $10 \%$, and it is associated with the incidence of MAE, including death, stroke, or hemolytic anemia ${ }^{[43,44]}$. The following features were identified as independent predictors of this serious complication in patients undergoing TMVR: an anterior leaflet length $>20 \mathrm{~mm}$, a small native LVOT $\left(<18 \mathrm{~mm}\right.$ ), an aorto-mitral annular angle $<115^{\circ}$, a reduced ventricular cavity (left ventricular end-diastolic diameter $<48 \mathrm{~mm}$ ), a significant septal bulge, and a predicted neo-LVOT $\leq 1.7 \mathrm{~cm}^{2[45,46]}$. Two interventional techniques have been described to prevent this major problem in selected cases with good outcomes: the laceration of the anterior MV leaflet and alcohol septal ablation ${ }^{[77,48]}$.

Yoon et al. ${ }^{[43]}$ evaluated outcomes in 248 patients who underwent TMVR (ViV and ViR in 176 and 72 patients, respectively). The indications for procedure were degenerated bioprosthesis and failed 

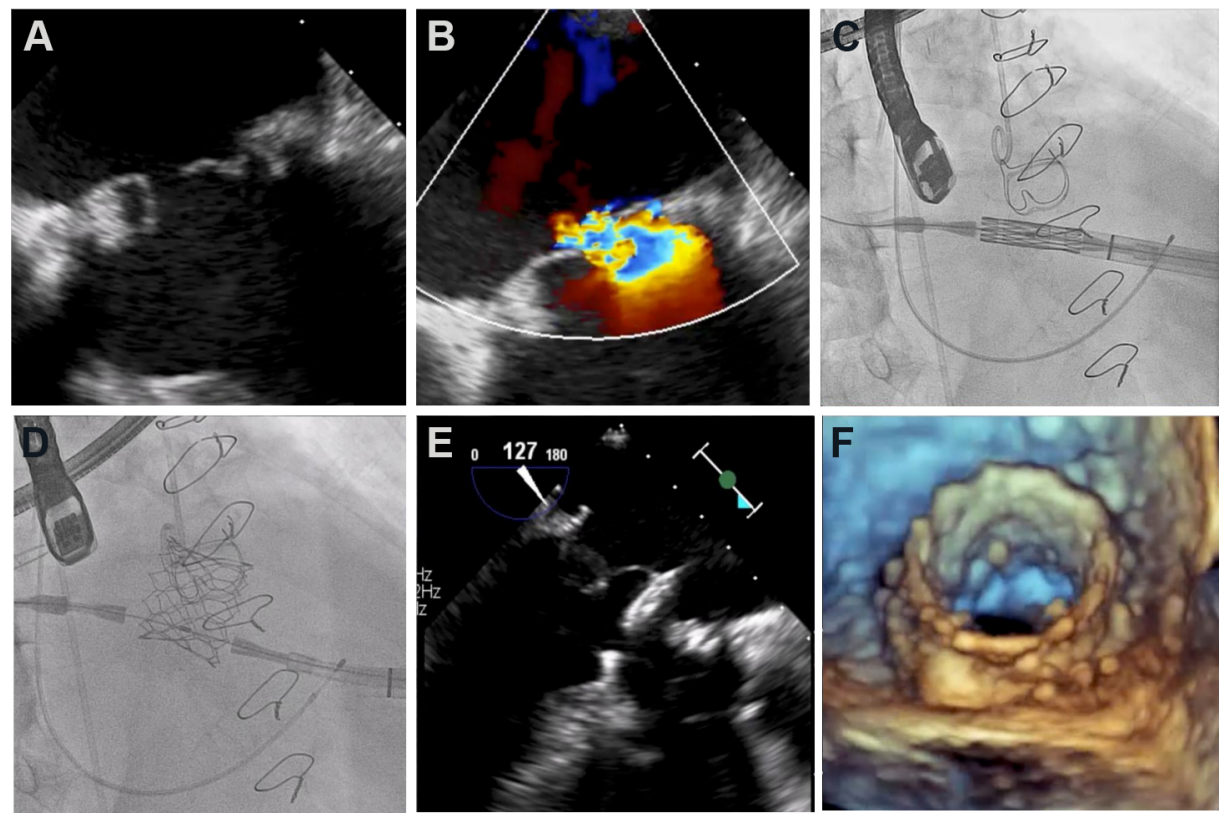

Figure 2. (A, B) Transesophageal echocardiogram showing degenerated mitral valve bioprosthesis with severe mitral regurgitation. (C, D) Transapical transcatheter mitral valve in valve procedure. (E, F) Transesophageal echocardiogram with final result.

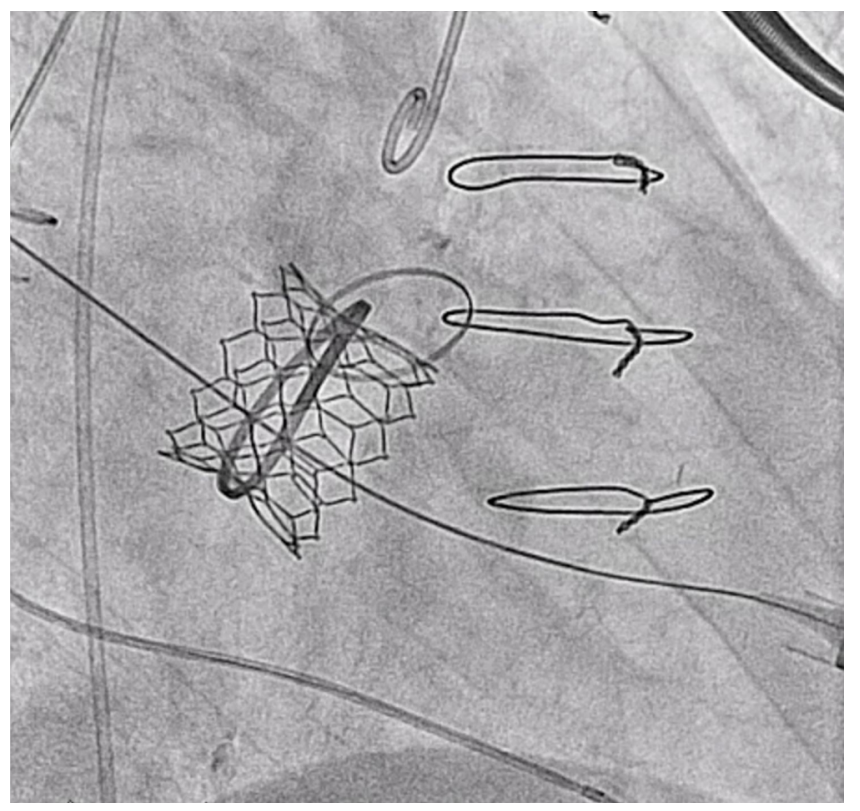

Figure 3. Transcatheter mitral valve in ring procedure.

annuloplasty rings, and $M R \geq 3$ was present in $76.6 \%$ of patients. Device success rate achieved was adequate in both groups; however, technical results presented higher success in ViV group. Recurrence of significant MR and all-cause mortality at 1 year were more frequent in ViR group ${ }^{[43]}$. Similar results at mid-term follow up were reported by Simonato et al. ${ }^{[42]}$ in 1079 patients (857 ViV, $222 \mathrm{ViR}$ ) with a mean age of 73.5 years. Survival rate evaluated at 4 years was higher in $\mathrm{ViV}$ patients (62.5\% vs. 49.5\%), and higher residual MR was observed in ViR group ${ }^{[42]}$. 
There is a lack of studies comparing transcatheter replacement and repeated surgery. Kamioka et al. ${ }^{[4]}$ compared clinical and echocardiographic outcomes after surgical redo mitral valve replacement and TMVR. Sixty-two patients underwent TMVR and 59 underwent redo surgery (MR was the procedural reason in $50 \%$ and $55 \%$, respectively). Mean age in the TMVR group was 74.9 years with an STS score of $12.8 \%$, while the redo surgery group had a lower STS score $(8.7 \%)$ and younger patients (63.7 years). There was a lower incidence of major bleeding and atrial arrhythmias and a shortening in days of admission in the TMVR group. Mortality at one year was similar with both strategies in the entire population (TMVR $11.3 \%$ vs. redo surgery $11.9 \%$ ), with no differences in residual transvalvular gradient or MR recurrence (TMVR 3.8\% vs. redo surgery $5.6 \%)^{[49]}$

Preprocedural exhaustive evaluation of the anatomy is particularly important before TMVR in order to select the best access route and the prosthetic valve type and size ${ }^{[50,51]}$. This includes transthoracic and TEE to evaluate the underlying mechanism of prior surgical failure and the anatomical characteristics of the interatrial septum and apex, as well as to discard the existence of atrial thrombosis. Moreover, computed tomography is mandatory to deeply address the structure or the bioprosthetic valve or the type of annuloplasty ring and anticipate LVOT obstruction after TMVR. In addition, TEE and fluoroscopy are used for procedural guidance, and fusion imaging software may further facility device deployment ${ }^{[52]}$.

Current evidence suggests that TMVR is an appealing and promising option for patients with failed surgical bioprosthesis and annuloplasty rings. Nevertheless, there are still important challenges that should be addressed in the following years, such as the universalization of the transeptal route; the impact of high transmitral gradient; the role of dedicated transcatheter MV prosthesis; the incidence of LVOT; the need for concomitant treatment of tricuspid regurgitation, if present; how to improve outcomes of ViR procedure; and long-term durability of transcatheter prosthetic valves in mitral position ${ }^{[53]}$.

\section{Percutaneous mitral paravalvular leak closure}

Given the high surgical risk for repeated surgery and not-infrequent recurrence after redo open-heart procedure, percutaneous closure of PVL is becoming a more common approach ${ }^{[54]}$. This increasing experience is leading to moderate to high rates of success, exceeding $90 \%$ in very high-volume institutions, with low incidence of periprocedural complications ${ }^{[55]}$. Sorajja et al. ${ }^{[55]}$ analyzed 30 -day outcomes of 115 patients with PVL (78\% MV PVL) undergoing percutaneous closure $70 \pm 77$ months after the index MVS. The main clinical indication was HF (93\% of patients) and most patients had multiple comorbidities (STS score $6.9 \% \pm 5.6 \%)$. Acute procedural success was achieved in $76 \%$ of cases and the Amplatzer Vascular Plug (AVP) II (Abbott, Santa Clara, CA, USA) was the device most frequently used (84\%). The incidence of mayor adverse clinical events at 30 days was $8.7 \%$. Likewise, Alkhouli et al. ${ }^{[56]}$ assessed in hospital and midterm outcomes in 231 patients undergoing PVL closure. Successful percutaneous PVL closure was achieve in $70 \%$ of cases and related to a higher survival at 3-year follow-up compared to patients with significant residual PVL. A recent series from the same working group compared 195 patients undergoing percutaneous PVL closure and 186 patients undergoing redo MVS. Even though technical success was higher in the surgical group ( $95.5 \%$ vs. $70.1 \%)$, MAE were less frequent in the percutaneous approach, including in-hospital mortality (3.1\% vs. 8.6\%), and reinterventions were similar in both groups at 4-year follow up (11.4\% and $17.2 \%$ in the percutaneous and surgical groups, respectively) ${ }^{[56]}$.

This kind of procedure is usually technically demanding and, therefore, preimplantation planning and patient selection play a key role in achieving optimal results. In this regard, $3 \mathrm{D}$ imaging is the cornerstone for procedural planning and guidance ${ }^{[57]}$. 3D-TEE allows identifying the PVL, evaluating the severity of MR, and carrying out a comprehensive examination of the anatomy of the prosthetic valve and the MV annulus 

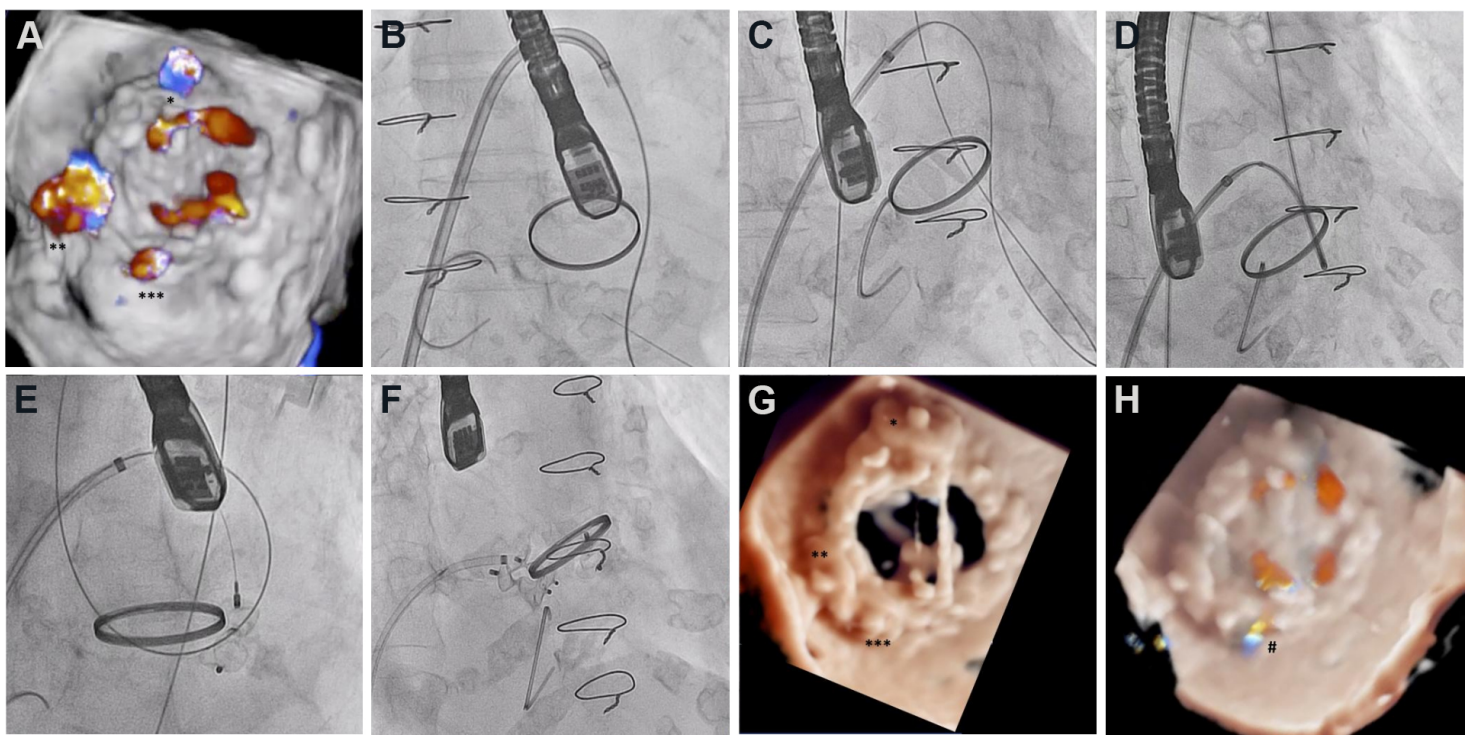

Figure 4. Percutaneous closure of mitral paravalvular leak. (A) Severe paravalvular leak after surgical mitral valve replacement. (B-F) Arteriovenous loop to deploy 3 Amplatzer Vascular Plug III devices. (G, H) Final result with mild residual paravalvular leak and without interference with prosthetic discs.

for device selection. While TEE is usually the main preintervention diagnostic imaging tool, computed tomography can also be useful in selected cases. For procedural guidance, 2D-TEE can display two simultaneous perpendicular planes defining four opposed cardinal-like points to orientate operator's maneuvers: atrial septum vs. left atrial appendage and aortic valve vs. posterior aspect. Complementarily, fluoroscopy helps identify the position of the steerable catheter and the occluder device relative to the prothesis discs and hinge. Usually, the preferred approach for mitral PVL closure is to wire the defect retrogradely from the LV aided by the MR flow, and it is more frequently performed via the femoral vein through a transseptal puncture, although the transapical route can also be used. Device deployment may require high support, which can be normally achieved through arteriovenous loops and buddy wire techniques. The mobility of the prosthetic discs and the anchorage of the device should be carefully assessed before complete release of the occluder in order to avoid prosthesis impingement and device embolization [Figure 4].

Device selection for percutaneous PVL closure is based on the anatomical features of the defect and the surrounding structures. The lack of devices specifically designed for this purpose has hampered this technique, so that treatment alternatives are limited to the off-label use of occluders dedicated to fix other cardiac defects. All of these devices have a self-expanding nitinol-based mesh with different types of disks and waists, allowing stable anchoring within the defect. Among the multitude of non-specific occluding devices that have been tried for this purpose, the Amplatzer Vascular Plug III (Abbott, Santa Clara, CA, USA) has become one of the most commonly used, mainly due to its oval morphology, flexible structure, and easy retrieval at all stages of deployment ${ }^{[58]}$.

\section{CONCLUSIONS}

The recurrence of MR after surgery is associated with increased morbidity and mortality. Transcatheter intervention techniques represent a safer and effective alternative for patients with multiple comorbidities or at high surgical risk. 


\section{DECLARATIONS}

\section{Authors' contributions}

Drafting the manuscript: Echarte-Morales J, Minguito-Carazo C, Benito-González T

Conception and design of the manuscript and revision: Estévez-Loureiro R, Garrote-Coloma C, Pérez de Prado A, Fernández-Vázquez F

All authors have given final approval of the version to be published.

\section{Availability of data and materials}

Not applicable.

\section{Financial support and sponsorship}

Not applicable.

\section{Conflicts of interest}

Estévez-Loureiro R is proctor for Mitraclip.

\section{Ethical approval and consent to participate}

Not applicable.

\section{Consent for publication}

Not applicable.

\section{Copyright}

(c) The Author(s) 2021.

\section{REFERENCES}

1. Nkomo VT, Gardin JM, Skelton TN, Gottdiener JS, Scott CG, Enriquez-Sarano M. Burden of valvular heart diseases: a populationbased study. Lancet 2006;368:1005-11. DOI PubMed

2. Enriquez-Sarano M, Akins CW, Vahanian A. Mitral regurgitation. Lancet 2009;373:1382-94. DOI PubMed

3. Reddy YNV, Nishimura RA. Not all secondary mitral regurgitation is the same - potential phenotypes and implications for mitral repair. JAMA Cardiology 2020;5:1087-8. DOI PubMed

4. Otto CM, Nishimura RA, Bonow RO, et al; Writing Committee Members. 2020 ACC/AHA Guideline for the management of patients with valvular heart disease: a report of the American College of Cardiology/American Heart Association Joint Committee on Clinical Practice Guidelines. J Am Coll Cardiol 2021;77:e25-197. DOI PubMed

5. Petrus AHJ, Dekkers OM, Tops LF, Timmer E, Klautz RJM, Braun J. Impact of recurrent mitral regurgitation after mitral valve repair for functional mitral regurgitation: Long-term analysis of competing outcomes. Eur Heart J 2019;40:2206-14. DOI PubMed

6. Enriquez-Sarano M, Sundt TM. Early surgery is recommended for mitral regurgitation. Circulation 2010;121:804-11. DOI PubMed

7. Badhwar V, Peterson ED, Jacobs JP, et al. Longitudinal outcome of isolated mitral repair in older patients: results from 14,604 procedures performed from 1991 to 2007. Ann Thorac Surg 2012;94:1870-7. DOI PubMed

8. McNeely CA, Vassileva CM. Long-term outcomes of mitral valve repair versus replacement for degenerative disease: a systematic review. Curr Cardiol Rev 2015;11:157-62. DOI PubMed PMC

9. Vassileva CM, Mishkel G, McNeely C, et al. Long-term survival of patients undergoing mitral valve repair and replacement: a longitudinal analysis of medicare fee-for-service beneficiaries. Circulation 2013;127:1870-6. DOI PubMed

10. Gammie JS, O'Brien SM, Griffith BP, Ferguson TB, Peterson ED. Influence of hospital procedural volume on care process and mortality for patients undergoing elective surgery for mitral regurgitation. Circulation 2007;115:881-7. DOI PubMed

11. Wu AH, Aaronson KD, Bolling SF, Pagani FD, Welch K, Koelling TM. Impact of mitral valve annuloplasty on mortality risk in patients with mitral regurgitation and left ventricular systolic dysfunction. J Am Coll Cardiol 2005;45:381-7. DOI PubMed

12. Goldstein D, Moskowitz AJ, Gelijns AC, et al. Two-year outcomes of surgical treatment of severe ischemic mitral regurgitation. $N$ Engl J Med 2016;374:344-53. DOI PubMed PMC

13. Hung J, Papakostas L, Tahta SA, et al. Mechanism of recurrent ischemic mitral regurgitation after annuloplasty: continued LV remodeling as a moving target. Circulation 2004;110:II85-90. DOI PubMed

14. Suri RM, Clavel MA, Schaff HV, et al. Effect of Recurrent mitral regurgitation following degenerative mitral valve repair: long-term analysis of competing outcomes. J Am Coll Cardiol 2016;67:488-98. DOI PubMed

15. Chikwe J, Toyoda N, Anyanwu AC, et al. Relation of mitral valve surgery volume to repair rate, durability, and survival. $J$ Am Coll Cardiol 2017:S0735-1097(17)30677. DOI PubMed 
16. Bourguignon T, Bouquiaux-Stablo AL, Loardi C, et al. Very late outcomes for mitral valve replacement with the Carpentier-Edwards pericardial bioprosthesis: 25-year follow-up of 450 implantations. J Thorac Cardiovasc Surg 2014;148:2004-11.e1. DOI PubMed

17. Pibarot P, Dumesnil JG. Prosthetic heart valves: selection of the optimal prosthesis and long-term management. Circulation 2009;119:1034-48. DOI PubMed

18. Duncan BF, McCarthy PM, Kruse J, et al. Paravalvular regurgitation after conventional aortic and mitral valve replacement: a benchmark for alternative approaches. J Thorac Cardiovasc Surg 2015;150:860-8.e1. DOI PubMed

19. Hammermeister K, Sethi GK, Henderson WG, Grover FL, Oprian C, Rahimtoola SH. Outcomes 15 years after valve replacement with a mechanical versus a bioprosthetic valve: Final report of the Veterans Affairs randomized trial. J Am Coll Cardiol 2000;36:1152-8. DOI PubMed

20. Safi AM, Kwan T, Afflu E, Kamme A Al, Salciccioli L. Paravalvular regurgitation: A rare complication following valve replacement surgery. Angiology 2000;51:479-87. DOI PubMed

21. Genoni M, Franzen D, Vogt P, et al. Paravalvular leakage after mitral valve replacement: Improved long-term survival with aggressive surgery? Eur J Cardio-thoracic Surg 2000;17:14-9. DOI PubMed

22. Onorati F, Perrotti A, Reichart D, et al. Surgical factors and complications affecting hospital outcome in redomitral surgery: insights from a multicentre experience. Eur J Cardio-thoracic Surg 2016;49:e127-33. DOI PubMed

23. Vohra HA, Whistance RN, Roubelakis A, et al. Outcome after redo-mitral valve replacement in adult patients: a 10-year single-centre experience. Interact Cardiovasc Thorac Surg 2012;14:575-9. DOI PubMed PMC

24. Estévez-Loureiro R, Benito-González T, Garrote-Coloma C, et al. Percutaneous mitral repair: current and future devices. Ann Transl Med 2020;8:963. DOI PubMed PMC

25. Shah M, Jorde UP. Percutaneous mitral valve interventions (repair): current indications and future perspectives. Front Cardiovasc Med 2019;6:88. DOI PubMed PMC

26. Lim DS, Kunjummen BJ, Smalling R. Mitral valve repair with the mitraclip device after prior surgical mitral annuloplasty. Catheter Cardiovasc Interv 2010;76:455-9. DOI PubMed

27. Pleger ST, Geis N, Kreusser M, et al. Percutaneous mitral valve repair in recurrent severe mitral valve regurgitation after mitral annuloplasty: MitraClip-in-the-ring as a complementary strategy. Herz 2019;46:54-60. DOI PubMed

28. Niikura H, Bae R, Gössl M, Sun B, Mudy K, Sorajja P. Transcatheter Mitral valve repair of recurrent mitral regurgitation following mitral surgery. JACC Cardiovasc Interv 2019;12:1395-7. DOI PubMed

29. Braun D, Frerker C, Körber MI, et al. Percutaneous edge-to-edge repair of recurrent severe mitral regurgitation after surgical mitral valve repair. J Am Coll Cardiol 2017;70:504-5. DOI PubMed

30. Grasso C, Ohno Y, Attizzani GF, et al. Percutaneous mitral valve repair with the MitraClip system for severe mitral regurgitation in patients with surgical mitral valve repair failure. J Am Coll Cardiol 2014;63:836-8. DOI PubMed

31. Estévez-Loureiro R, Arzamendi D, Carrasco-Chinchilla F, Amat-Santos IJ, Freixa X, Suárez de Lezo J. Usefulness of MitraClip for the treatment of mitral regurgitation secondary to failed surgical annuloplasty. Rev Esp Cardiol (Engl Ed) 2016;69:446-8. DOI PubMed

32. Saji M, Rossi AM, Ailawadi G, Dent J, Ragosta M, Scott Lim D. Adjunctive intracardiac echocardiography imaging from the left ventricle to guide percutaneous mitral valve repair with the mitraclip in patients with failed prior surgical rings. Catheter Cardiovasc Interv 2016;87:E75-82. DOI PubMed

33. Alkhouli M, Kawsara A, Alqahtani F, Badhwar V, Sengupta PP. Transcatheter mitral valve repair following ring annuloplasty: technical challenges and the role of invasive hemodynamics. JACC Cardiovasc Interv 2020;13:e207-9. DOI PubMed

34. Kanda BS, Jay D, Farivar RS, Sorajja P. Leaflet-to-annuloplasty ring clipping for severe mitral regurgitation. JACC Cardiovasc Interv 2016;9:e63-4. DOI PubMed

35. Hanson ID, Hanzel GS, Shannon FL. Mitral valve repair after annuloplasty ring dehiscence using MitraClip. Catheter Cardiovasc Interv 2016;88:301-6. DOI PubMed

36. Avenatti E, El-Tallawi KC, Vukicevic M, Lawrie GM, Barker CM, Little SH. Percutaneous repair for recurrent mitral regurgitation after surgical repair: a mitraclip experience. Struct Hear 2018;2:147-54. DOI

37. Walther T, Falk V, Dewey T, et al. Valve-in-a-valve concept for transcatheter minimally invasive repeat xenograft implantation. $J$ Am Coll Cardiol 2007;50:56-60. DOI PubMed

38. Eng MH, Wang DD. Transseptal transcatheter mitral valve replacement for post-surgical mitral failures. Interv Cardiol Rev 2018;13:77-80. DOI PubMed PMC

39. Whisenant B, Kapadia SR, Eleid MF, et al. One-year outcomes of mitral valve-in-valve using the SAPIEN 3 transcatheter heart valve. JAMA Cardiol 2020;5:1245-52. DOI PubMed PMC

40. Cheung A, Webb JG, Barbanti M, et al. 5-Year experience with transcatheter transapical mitral valve-in-valve implantation for bioprosthetic valve dysfunction. J Am Coll Cardiol 2013;61:1759-66. DOI PubMed

41. Maisano F, Taramasso M. Mitral valve-in-valve, valve-in-ring, and valve-in-MAC: the Good, the Bad, and the Ugly. Eur Heart $J$ 2019;40:452-5. DOI PubMed

42. Simonato M, Whisenant B, Ribeiro HB, et al. Transcatheter mitral valve replacement after surgical repair or replacement: comprehensive mid-term evaluation of valve-in-valve and valve-in-ring implantation from the VIVID registry. Circulation 2021;143:104-16. DOI PubMed

43. Yoon SH, Whisenant BK, Bleiziffer S, et al. Transcatheter mitral valve replacement for degenerated bioprosthetic valves and failed annuloplasty rings. J Am Coll Cardiol 2017;70:1121-31. DOI PubMed

44. Paradis JM, Del Trigo M, Puri R, Rodés-Cabau J. Transcatheter valve-in-valve and valve-in-ring for treating aortic and mitral surgical prosthetic dysfunction. J Am Coll Cardiol 2015;66:2019-37. DOI PubMed 
45. Yoon SH, Bleiziffer S, Latib A, et al. Predictors of left ventricular outflow tract obstruction after transcatheter mitral valve replacement. JACC Cardiovasc Interv 2019;12:182-93. DOI PubMed

46. Bapat V, Pirone F, Kapetanakis S, Rajani R, Niederer S. Factors influencing left ventricular outflow tract obstruction following a mitral valve-in-valve or valve-in-ring procedure, part 1. Catheter Cardiovasc Interv 2015;86:747-60. DOI PubMed

47. Babaliaros VC, Greenbaum AB, Khan JM, et al. Intentional percutaneous laceration of the anterior mitral leaflet to prevent outflow obstruction during transcatheter mitral valve replacement: first-in-human experience. JACC Cardiovasc Interv 2017;10:798-809. DOI PubMed PMC

48. Guerrero M, Wang DD, Himbert D, et al. Short-term results of alcohol septal ablation as a bail-out strategy to treat severe left ventricular outflow tract obstruction after transcatheter mitral valve replacement in patients with severe mitral annular calcification. Catheter Cardiovasc Interv 2017;90:1220-6. DOI PubMed

49. Kamioka N, Babaliaros V, Morse MA, et al. Comparison of clinical and echocardiographic outcomes after surgical redo mitral valve replacement and transcatheter mitral valve-in-valve therapy. JACC Cardiovasc Interv 2018;11:1131-8. DOI PubMed

50. Little SH, Bapat V, Blanke P, Guerrero M, Rajagopal V, Siegel R. Imaging guidance for transcatheter mitral valve intervention on prosthetic valves, rings, and annular calcification. JACC Cardiovasc Imaging 2020;14:22-40. DOI PubMed

51. Blanke P, Dvir D, Cheung A, et al. A simplified D-shaped model of the mitral annulus to facilitate CT-based sizing before transcatheter mitral valve implantation. J Cardiovasc Comput Tomogr 2014;8:459-67. DOI PubMed PMC

52. Nez-Gil IJ, Gonalves A, Rodrguez E, et al. Transapical mitral valve-in-valve implantation: a novel approach guided by threedimensional transoesophageal echocardiography. Eur J Echocardiogr 2011;12:335-7. DOI PubMed

53. Rodés-Cabau J, Kalavrouziotis D. Transcatheter mitral valve-in-valve replacement: the new gold standard for treating mitral bioprosthesis failure? JACC Cardiovasc Interv 2018;11:1139-41. DOI PubMed

54. García-Borbolla Fernández R, Sancho Jaldón M, Calle Pérez G, et al. Percutaneous treatment of mitral valve periprosthetic leakage. an alternative to high-risk surgery? Rev Esp Cardiol 2009;62:438-41. DOI PubMed

55. Sorajja P, Cabalka AK, Hagler DJ, Rihal CS. Percutaneous repair of paravalvular prosthetic regurgitation: acute and 30-day outcomes in 115 patients. Circ Cardiovasc Interv 2011;4:314-21. DOI PubMed

56. Alkhouli M, Zack CJ, Sarraf M, et al. Successful percutaneous mitral paravalvular leak closure is associated with improved midterm survival. Circ Cardiovasc Interv 2017;10:e05730. DOI PubMed

57. Cortés M, García E, García-Fernandez MA, Gomez JJ, Perez-David E, Fernández-Avilés F. Usefulness of transesophageal echocardiography in percutaneous transcatheter repairs of paravalvular mitral regurgitation. Am J Cardiol 2008;101:382-6. DOI PubMed

58. Cruz-Gonzalez I, Rama-Merchan JC, Arribas-Jimenez A, et al. Paravalvular leak closure with the Amplatzer Vascular Plug III Device: immediate and short-term results. Rev Esp Cardiol (Engl Ed) 2014;67:608-14. DOI PubMed 